\title{
Surface hardening of aluminum alloys by chemical nickel plating
}

\author{
S. A. Zemljakov ${ }^{1, \dagger}$, A. M. Guriev²,3, M. A. Guriev², S. G. Ivanov ${ }^{4}$ \\ †gurievam@mail.ru
}

\author{
${ }^{1}$ JSC “Altai Precision Products Plant”, 6/2 Kosmonavtov avenue, 656023, Barnaul, Russia \\ ${ }^{2}$ Altai State Technical University after I.I. Polzunov, 46 Lenin avenue, 656038, Barnaul, Russia \\ ${ }^{3}$ Wuhan Textile University, 1 Fang Zhi Road, 430073, Wuhan, China \\ ${ }^{4}$ LLC “Hardening Technologies”, 39a Turinogorskaya st., 656063, Barnaul, Russia
}

\begin{abstract}
Aluminum AK4 (2618, ANSI H35.2) and V95 (AA7075, ANSI H35.2) alloys have been hardened by the method of chemical nickel plating. The distribution of microhardness over the coating section has been studied. The hardness of the hardened V95 alloy has been found 1.9 times higher than that of the hardened AK4 alloy. It has been shown that the parameters of the nickel coating (thickness, microhardness, phase composition) depend on the chemical composition of the processed aluminum alloy. When processing the V95 alloy, maximum values of coating thickness and microhardness have been observed. It has been found that during the thermal treatment of chemically nickel-plated V95 alloy, an AlNi intermetallic can form at the border between the coating and base material, which has a higher hardness than the nickel coating. On the border of nickel coating and AK4 alloy no intermetallic layer is formed. It has been shown that the maximum microhardness is achieved in the lower part of the coating, which amounts about 40 to $50 \%$ of its thickness. When approaching the interface between the coating and coated material, the microhardness increases monotonically up to a maximum and then decreases monotonically to the value corresponding to the base material. On the diffractogram of an aluminum V95 alloy sample after thermal treatment one observes a contribution of AlNi intermetallic to the main peak. On the diffractogram of the aluminum AK4 alloy sample after thermal treatment only Al-Ni solid solution is observed. The formation of a nickel coating with such a distribution of microhardness values on V95 aluminum alloy can allow for breaking-in of the hardened product during exploitation that is expected to influence favorably on the operational life of an article as a whole.
\end{abstract}

Keywords: aluminum, nickel, coating.

\section{Поверхностное упрочнение алюминиевых сплавов химическим никелированием}

\author{
Земляков С. А. ${ }^{1, \dagger}$, Гурьев А. М. ${ }^{2,3}$, Гурьев М. А. ${ }^{2}$, Иванов С. Г. ${ }^{4}$ \\ ${ }^{1} \mathrm{AO}$ «Алтайский завод прецизионных изделий», пр. Космонавтов 6/2, 656023, Барнаул, Россия \\ ${ }^{2}$ Алтайский государственный технический университет им. И.И. Ползунова, пр. Ленина 46, 6560386 Барнаул, Россия \\ ${ }^{3}$ Уханьский текстильный университет, Фань Жи Роад 1, 430073, Ухань, КНР \\ ${ }^{4} \mathrm{OOO}$ «Технологии упрочнения», ул. Туриногорская 39a, 656063, Барнаул, Россия
}

В работе проведено упрочнение алюминиевых сплавов АК4 и В95 методом химического никелирования. Полученные покрытия исследованы с помощью оптической микроскопии, рентгенофазового анализа, изучено распределение микротвердости по сечению покрытия. Измерена твердость упрочненных образцов, которая для упрочненного сплава В95 в 1,9 раза выше чем для упрочненного сплава АК4. Установлено, что параметры никелевого покрытия (толщина, микротвердость, фазовый состав) зависят от химического состава обрабатываемого алюминиевого сплава. Максимальные значения толщины покрытия и микротвердости наблюдаются при никелировании и последующей термической обработке сплава В95. Установлено, что при термической обработке химически никелированного алюминиевого сплава B95 возможно образование интерметаллида AlNi на границе покрытия и основного материала, имеющего большую твердость, чем основное никелевое покрытие. На границе никелевого покрытия и сплава АК 4 интерметаллидная прослойка не образуется. Установлено, что максимальная микротвердость достигается в нижней части покрытия, составляющей 40-50\% от его толщины и по мере приближения к границе раздела покрытия и обрабатываемого материала микротвердость монотонно возрастает до максимума, далее - монотонно же убывает до микротвердости, соответствующей основному материалу. На дифрактограмме образца из алюминиевого сплава В95 после термической обработки наблюдается появление в главном пике интерметаллида AlNi. На дифрактограмме образца из алюминиевого сплава АК4 после термической обработки наблюдается только твердый раствор Al-Ni. Образование никелевого покрытия с таким распределением значений микротвердости на алюминиевом сплаве В95 позволит упрочненному изделию «прирабатываться» в процессе эксплуатации, что должно благоприятно влиять на ресурс работы изделия в целом.

Ключевые слова: алюминий, никель, покрытие. 


\section{1. Введение}

Алюминиевые сплавы находят широкое применение в промышленном производстве благодаря комплексу механических свойств наряду с малым весом. По сравнению со сталями и титановыми сплавами, алюминиевые сплавы имеют более низкую твердость, что сказывается на их износостойкости. Однако благодаря высокой технологичности и низкой стоимости, альтернативу алюминиевым сплавам при производстве малоинерционных деталей машин найти затруднительно.

Так, в частности, быстродвижущиеся детали ткацких станков, в том числе и шестерни, в настоящее время изготавливают из алюминиевых сплавов типа дуралюмин. При этом ресурс работы таких шестерен достаточно низок, что приводит к значительному простою оборудования, связанному с необходимостью замены алюминиевых деталей, потерявших работоспособность в результате износа.

Одним из способов повышения износостойкости быстроизнашивающихся алюминиевых деталей является нанесение различных упрочняющих покрытий [1-6]. Наиболее часто применяются анодированные покрытия, представляющие собой пленку оксида алюминия, формируемую на поверхности упрочняемой детали в результате электрохимической обработки в различных электролитах. Однако, электрохимической обработке в растворах и расплавах электролитов деталей сложной формы, к которым относятся подающие шестерни ткацких станков, присущ такой недостаток, как высокая неравномерность анодированного покрытия в результате проявления рассеивающей способности электролитов и взаимного экранирования поверхностей. При этом на рабочих поверхностях шестерен формируются слои недостаточной толщины, тогда как на других поверхностях возможно формирование покрытий такой толщины, что происходит их растрескивание вследствие большой разницы объема между основным материалом и покрытием.

В настоящей работе для упрочнения поверхности применили нанесение интерметаллидных покрытий на основе системы Al-Ni. Как наиболее технологичное в случае упрочнения алюминиевых звездочек и шестерен выбрано нанесение никелевого покрытия способом химического осаждения с последующей термической обработкой для формирования интерметаллидных соединений системы Ni-Al.

\section{2. Материалы и методики}

В качестве исследуемых алюминиевых сплавов выбраны сплавы АК4 и В95. Исследовали образцы цилиндрической формы диаметром 12 и высотой 4 мм. Химическое осаждение никеля вели из водного раствора, содержащего в качестве основных компонентов сернокислый и уксуснокислый никель, фтористый натрий и фосфорноватистокислый натрий [6-8]. Для регулирования содержания фосфора в осаждающемся покрытии, использовали добавки гидрохлорида гидразина. Выдержку в растворе осаждения осуществляли в течение 1 - 1,5 ч, после чего образцы извлекали, промывали и просушивали. Термообработка образцов заключалась в выдержке их в предварительно прогретой до $400^{\circ} \mathrm{C}$ камерной печи в течение 40 мин. По истечении выдержки образцы извлекали из печи и охлаждали на воздухе [5-8].

Для пробоподготовки образцов и металлографических исследований полученных покрытий использовали прецизионный металлографический станок «MICRACUT-201», автоматический металлографический пресс «METAPRESS» и автоматический шлифовально-полировальный станок «DIGIPREP». Для шлифовки и полировки использовали абразивные шкурки зернистостью 320, 600, 1200 и 2500. Полировку осуществляли с использованием спиртовой эмульсии поликристаллических алмазов зернистостью 0,5 мкм. Суперфинишую полировку осуществляли с использованием основной коллоидной эмульсии оксида кремния зернистостью 0,05 мкм. Травление шлифов производили погружением в реактив Келлера на 3-7 с. Изучение микроструктуры и измерение микротвердости осуществляли при помощи программно-аппаратного комплекса «ThixometPro», включающего оптический микроскоп CarlZeissAxioObserver Z1m и полуавтоматический микротвердомер МН-6. Микротвердость покрытия определяли при нагрузке 100г, толщину слоя покрытия определяли по методикам [9-15]. Твердость упрочненного изделия определяли при нагрузке 1 кг по нормали к поверхности через слой покрытия. Рентгенофазовый анализ проводился на дифрактометре ДРОН-6 (CuK, $\lambda=1,5418 \AA$ ). Обработка экспериментальных данных осуществлялась с помощью пакета программ PDWin, предназначенного для автоматизации процесса обработки рентгенограмм. Для идентификации дифракционных максимумов использовалась картотека PDF-2 Meждународного центра дифракционных данных (ICDD). Элементный состав исходных образцов и образцов с покрытием изучали при помощи рентген-флуоресцентного анализатора X-MET 7500 и анализатора GNR Solaris CCD Plus.

\section{3. Результаты и обсуждение}

Микроструктура покрытия, полученного на алюминиевом сплаве АК4 представлена на рис. 1.

Дифрактограмма исходного образца содержит отражения, соответствующие Si и Al (рис. 2). Содержание фосфора в покрытии не превышает 0,7\% масс., фосфидов никеля выявить не удалось.

После нанесения покрытия и последующей обработки на дифрактограмме наблюдается увеличение диффузного фона и идентифицируется уширенный дифракционный пик $(2 \theta=44.50)$, с расщеплением в максимуме, соответствующим межплоскостным расстояниям $d=2.034 \AA, d=2.043 \AA$. Уширенный пик с небольшим смещением в сторону меньших углов может свидетельствовать об образовании твердых растворов на основе $\mathrm{Al}$ и $\mathrm{Ni}$, по наличию выраженного диффузного фона можно предположить образование зародышей интерметаллидных фаз $\mathrm{Ni}-\mathrm{Al}$. 

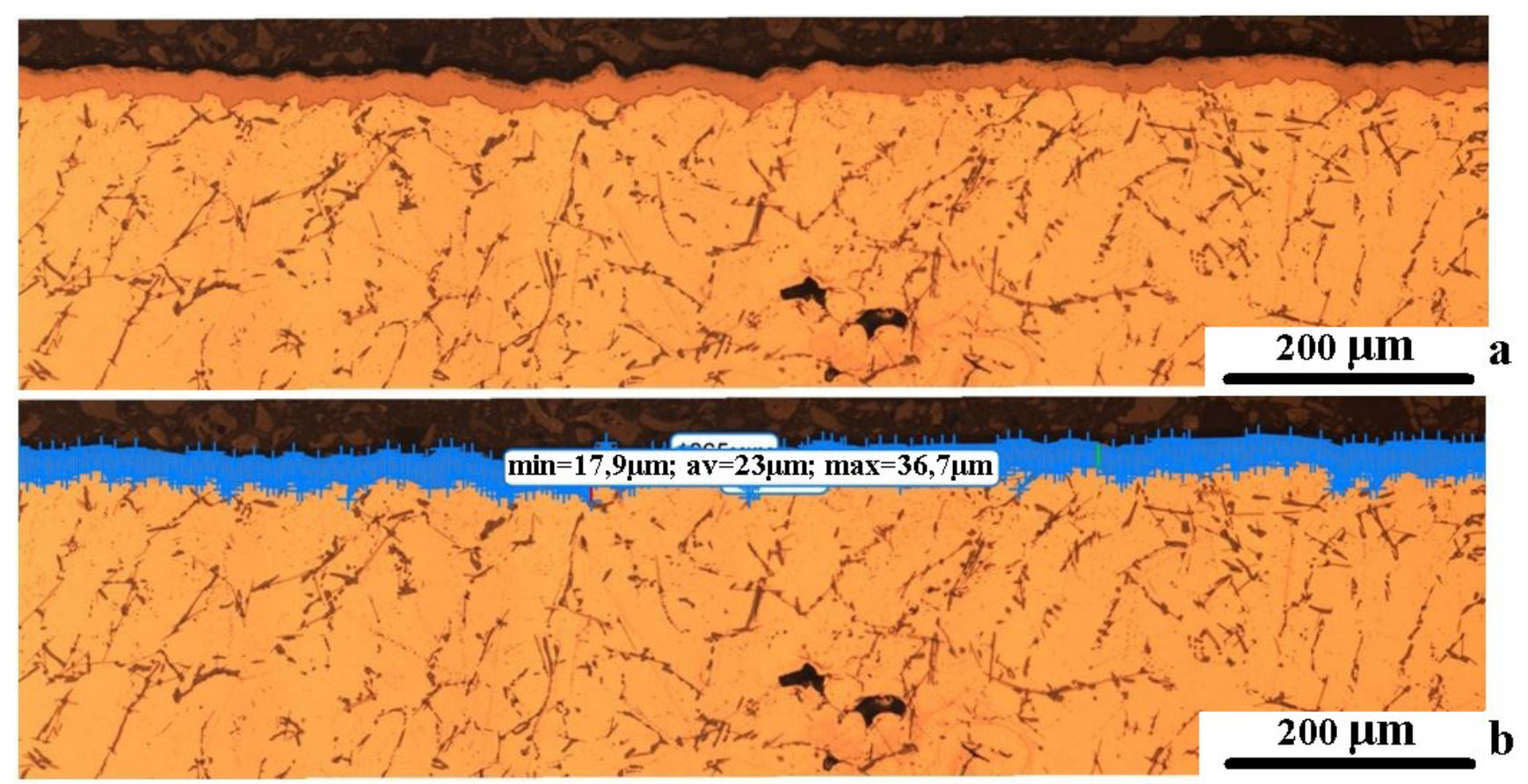

Рис. 1. Микроструктура (a) и толщина (b) никелевого покрытия на алюминиевом сплаве АК4.

Fig. 1. Microstructure (a) and thickness (b) of the nickel coating on the aluminum alloy 2618.
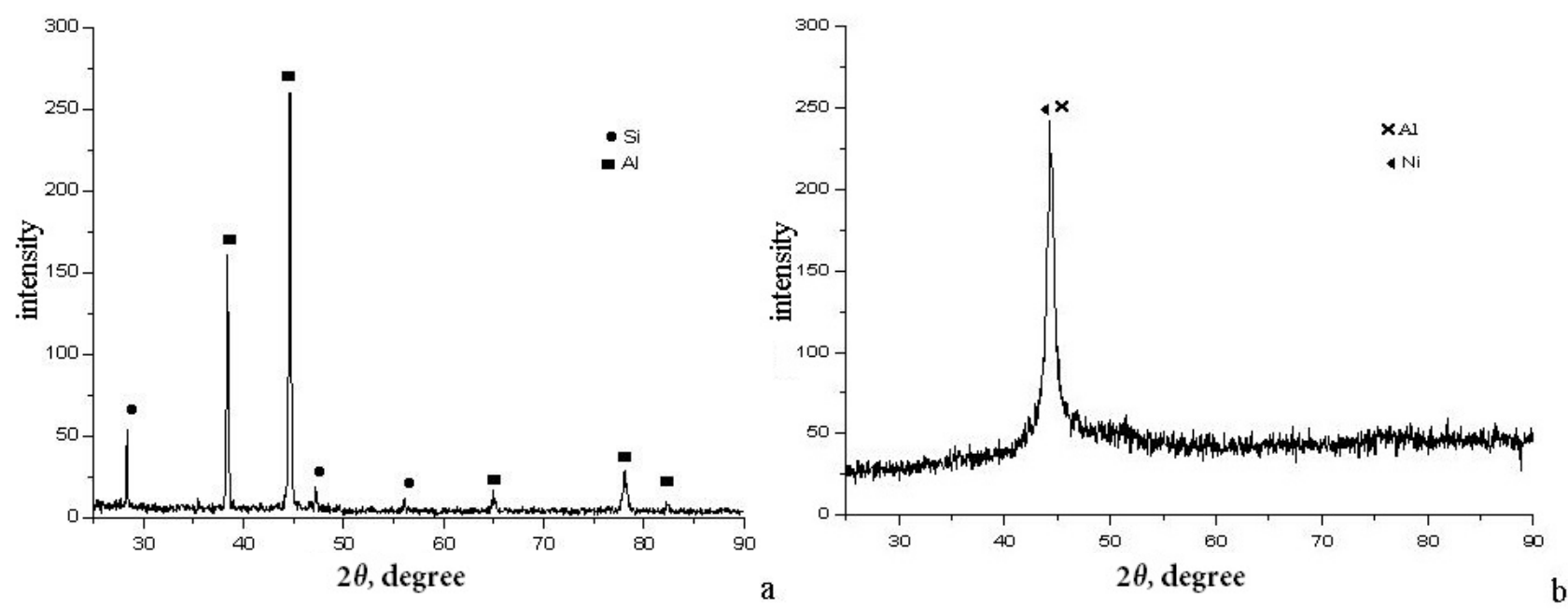

Рис. 2. Дифрактограммы исходного образца АК4 (а) и образца АК4 с нанесенным покрытием после обработки (b).

Fig. 2. Diffraction patterns of the original sample AK4 (a) and the coated sample 2618 after treatment (b).

Микроструктура покрытия на алюминиевом сплаве В95 представлена на рис. 3.

Дифрактограммы исходного образца алюминия В95 и образца с нанесенным никелевым покрытием до и после термической обработки представлены на рис. 4a, b, с, соответственно.

После термообработки происходит незначительный сдвиг основного пика в сторону меньших углов, соответственно происходят изменения в межплоскостном расстоянии решетки в сторону увеличения. Более подробно результаты анализа дифрактограмм представлены в таблице:
Табл. 1. Параметры пика на рис. 4. Table 1. Peak parameters in Fig. 4.

\begin{tabular}{|c|c|c|}
\hline & $\begin{array}{l}\text { До термооб- } \\
\text { работки (b) } \\
\text { Before heat } \\
\text { treatment (b) }\end{array}$ & $\begin{array}{c}\text { После термооб- } \\
\text { работки (c) } \\
\text { After heat } \\
\text { treatment (c) }\end{array}$ \\
\hline $\begin{array}{l}2 \theta, \text { град. } \\
2 \theta, \text { deg. }\end{array}$ & 44.46 & 44.31 \\
\hline$d, \AA$ & 2.035 & 2.042 \\
\hline $\begin{array}{c}I_{\text {max }}, \text { усл.ед. } \\
I_{\max } \text { conditional units }\end{array}$ & 586.7 & 770.7 \\
\hline $\begin{array}{l}\text { ПШПВ, град. } \\
\text { FWHM, deg. }\end{array}$ & 0.780 & 0.702 \\
\hline $\begin{array}{l}\text { Асимметрия } \\
\text { Asymmetry }\end{array}$ & 1.165 & 0.992 \\
\hline
\end{tabular}




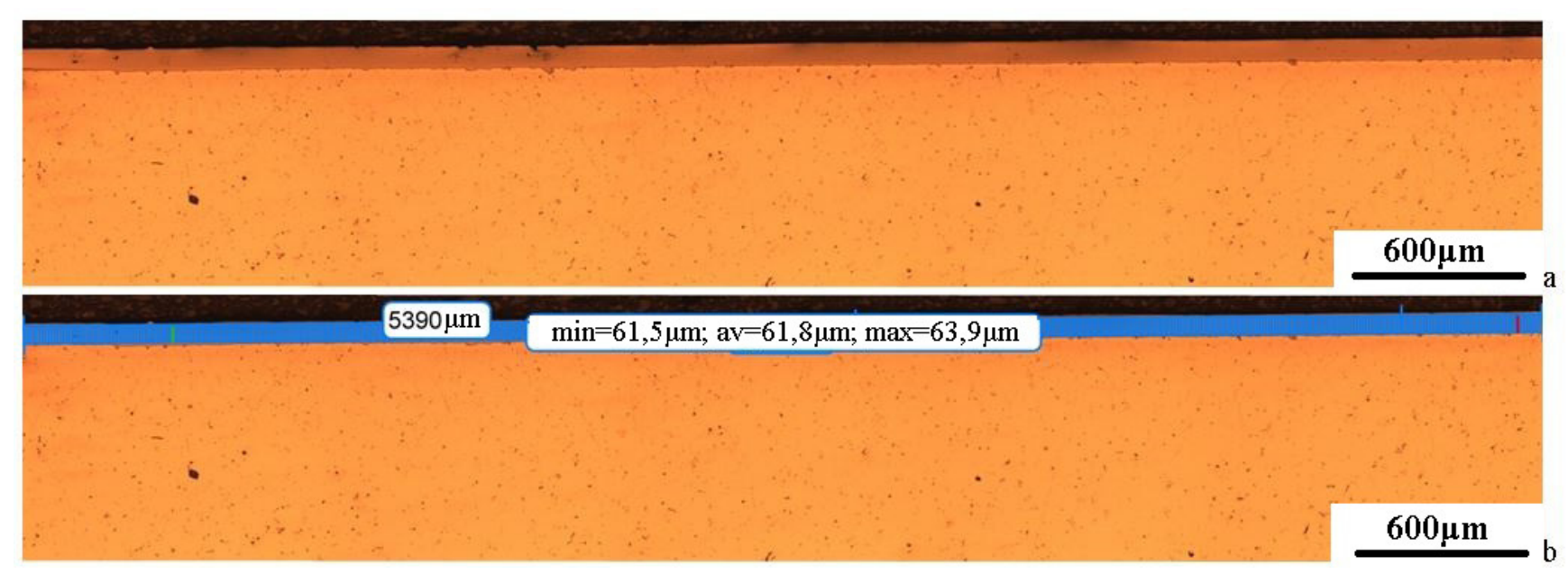

Рис. 3. Микроструктура (а) и толщина (b) никелевого покрытия на алюминиевом сплаве В 95.

Fig. 3. Microstructure (a) and thickness (b) of nickel coating on aluminum alloy AA7075.

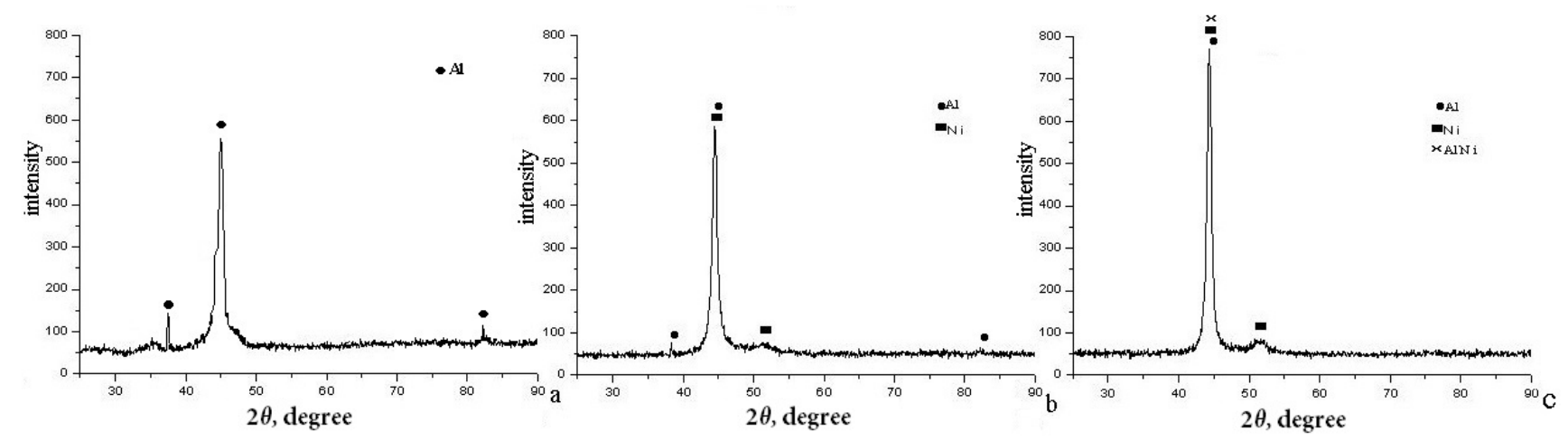

Рис.4. Дифрактограммы образца из алюминия В95 в исходном состоянии (а) с никелевым покрытием до (b) и после термообработки (c). Fig. 4. Diffraction patterns of a sample of aluminum AA7075 initial state (a) with nickel coating before (b) and after heat treatment (c).

Распределение значений микротвердости по сечению покрытия на алюминиевых сплавах АК4 и В95 представлено на рис. 5. Как следует из анализа полученных результатов толщина покрытия, определенная дюрометрическим и металлографическим способом в значительной степени коррелируют. Установлено, что максимальная микротвердость достигается в нижней части покрытия, составляющей $40-50 \%$ от толщины покрытия. По мере приближения к границе раздела покрытия и основного материала микротвердость монотонно возрастает до максимума, далее - монотонно же убывает до микротвердости, соответствующей основному материалу. Такое распределение микротвердости покрытия (рис. 5) позволяет упрочненной детали «прирабатываться» в процессе эксплуатации (снижается износ сопрягаемой детали) в результате притирки контактирующих поверхностей упрочненного изделия, что приводит к увеличению износостойкости изделия в целом $[16,17]$.

Твердость, измеренная при нагрузке 1 кг по нормали к поверхности через слой покрытия в случае сплава АК4 составила $410 \mathrm{HV}_{1}\left(93 \mathrm{HV}_{1}\right.$ для материала без покры- тия) и $776 \mathrm{HV}_{1}\left(165 \mathrm{HV}_{1}\right.$ для материала без покрытия) для сплава В95.

На дифрактограмме образца из алюминиевого сплава В95 после термической обработки наблюдается появление в главном пике интерметаллида $\mathrm{AlNi}$, о чем также косвенно может свидетельствовать увеличение параметра кристаллической решетки $d$, а также увеличение интенсивности пика и снижение параметров асимметрии пика ПШПВ.

\section{4. Заключение}

1. Показано, что параметры химического никелевого покрытия (толщина, микротвердость, химический и фазовый состав) зависят от химического состава обрабатываемого алюминиевого сплава.

2. Установлено, что при термической обработке химически никелированного алюминиевого сплава В95 возможно образование интерметаллида AlNi на границе покрытия и основного материала, имеющего большую твердость, чем никелевое покрытие. 


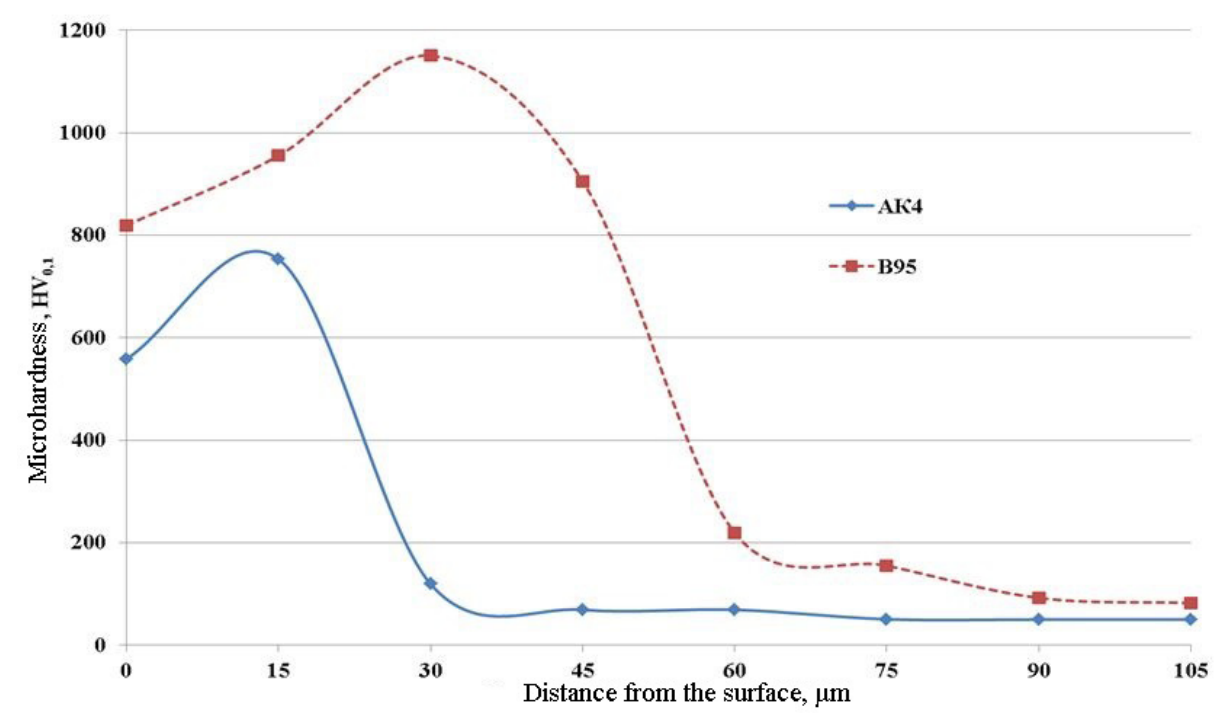

Рис.5. Распределение микротвердости по сечению никелевого покрытия на алюминиевых сплавах АК4 и В95 после термообработки. Fig. 5. Distribution of microhardness along the section of nickel coating on aluminum alloys 2618 and AA7075 after heat treatment.

\section{Литература/References}

1. Gurevich L.M., Shmorgun V.G., Slautin O.V., Bogdanov A.I. Sloistye intermetallidnye kompozity i pokrytija. M.: Metallurgizdat. 2016.346p. [Гуревич Л. М., Шморгун В. Г., Слаутин О. В., Богданов А. И. Слоистые интерметаллидные композиты и покрытия. М.: Металлургиздат. 2016. 346с.]

2. Lysak V.I., Kuzmin S.V. Explosive welding of metal layered composite materials. Paton Electric Welding Institute of the National Academy of Sciences of Ukraine. 2003. $117 \mathrm{p}$.

3. Trykov Ju.P., Gurevich L.M., Shmorgun V.G. Sloistye kompozity na osnove aljuminija i ego splavov M.: Metallurgizdat.2004.230p. [Трыков Ю. П., Гуревич Л. М., Шморгун В.Г. Слоистые композиты на основе алюминия и его сплавов М.: Металлургиздат. 2004. 230с.]

4. Anju M. Pillai, A. Rajendra, A.K. Sharma J. Coat. Technol. Res., 9 (6) 785-797 (2012). DOI 10.1007/s11998-012-9411-0

5. Dresvyannikov A. F., Ivshin Ya. V., and Khairullin M.G. Protection of Metals. 6 (36) pp. 551-554 (2000).

6. Nikandrova L.I. Himicheskie sposoby poluchenija metallicheskih pokrytij. Leningrad: Mashinostroenie. 1971. 104p. [Никандрова Л.И. Химические способы получения металлических покрытий. Ленинград: Машиностроение. 1971. 104c.]

7. Devyatkina T.I., Luchneva S.I., Fomicheva S.V., Rogozhin V.V., Gavrilov G.N., Naumov V.I., and Mukhalenko M.G. Russian Journal of Applied $\begin{array}{lllll}\text { Chemistry. } 8 & \text { (89) pp. } 1245-1251 & \text { (2016). DOI }\end{array}$ 10.1134/S107042721608005X

8. K. Hari Krishnan, S. John, K. N. Srinivasan, J. Praveen, M. Ganesan, P.M. Kavimani. Metallurgical and Materials Transactions A. 6 (37) 1917 (2006). DOI: 10.1007/s11661-006-0134-7
9. Ivanov S.G., Garmaeva I.A., Guriev M.A., Guriev A.M., Starostenkov M.D. Lecture Notes in Mechanical Engineering. 4922 (2015). DOI: 10.1007/978-3-319-15684-2_7

10. Ivanov S.G., Guriev A.M., Starostenkov M.D., Ivanova T. G., Levchenko A. A. Russian Physics Journal. 2 (57) 266 (2014). DOI:10.1007/s11182-014-0234-6

11. Kazakov A. A., Kiselev D. Metallography, Microstructure, and Analysis. DOI 10.1007/s13632-016-0289-6

12. Kazakov A.A., Ryaboshuk S., Lyubochko D., Chigintsev L. Microscopy and Microanalysis. 3 (21) 1775 (2015). Doi:10.1017/S1431927615009551

13. Kazakov A.A. and Kiselev D. Microscopy $\begin{array}{llllll}\text { and Microanalysis. } & 3 & \text { (21) } & 457 & \text { (2015). } & \text { DOI }\end{array}$ $10.1017 /$ S1431927615003086.

14. Kazakov A.A., Luong N.H., Kasakova E.I., Zorina E.M. Proceedings of the 32nd Annual Convention of the International Metallographic Society Held "Understanding Processing, Structure, Property and Behavior Correlations". Cincinati, Ohio ASM International. (1999) p. 133 - 142.

15. Kazakov A.A., Kovalev P.V., Myasnikov A.L., Drobinin A.A., Zinchenko S.D. Chernyie metally. 232 (2006) (in Russian). [Казаков A.A., Ковалев П.В., Мясников А.Л., Дробинин А.А., Зинченко С. Д. Черные металлы. 232 (2006).]

16. Garmaeva I.A., Lygdenov B.D., Dolgorov A.A. Fundamental'nye problemy sovremennogo materialovedenija. 1 (6) 19 (2009). [Гармаева И. А., Лыгденов Б. Д., Долгоров А.А. Фундаментальные проблемы современного материаловедения. 1 (6) 19 (2009).]

17. Himiko-termicheskaja obrabotka metallov i splavov: Spravochnik // Pod red. L. S. Ljahovicha. M.: Metallurgija, 1981. 424p. [Химико-термическая обработка металлов и сплавов: Справочник // Под ред. Л. С. Ляховича. М.: Металлургия, 1981.424 c]. 